\title{
A covalent peptide inhibitor of RGS4 identified in a focused one-bead, one compound library screen Rebecca A Roof ${ }^{1,3}$, David L Roman ${ }^{1,4}$, Samuel T Clements ${ }^{1}$, Katarzyna Sobczyk-Kojiro ${ }^{2}$, Levi L Blazer ${ }^{1}$, Shodai Ota ${ }^{1}$, Henry I Mosberg ${ }^{2}$ and Richard R Neubig*1
}

\begin{abstract}
Address: ${ }^{1}$ Department of Pharmacology, University of Michigan, 1301 MSRB III SPC 5632, 1150 W. Medical Center Dr, Ann Arbor, MI 48109, USA ${ }^{2}$ Department of Medicinal Chemistry, University of Michigan, 428 Church St, Ann Arbor, MI 48109, USA, ${ }^{3}$ Current address: Molecular Neuropharmacology Section, National Institute of Neurological Disorders and Stroke, National Institutes of Health, 5625 Fishers Ln, Bethesda, MD 20852, USA and ${ }^{4}$ Current address: College of Pharmacy, University of Iowa, 115 S. Grand Ave., Iowa City, IA 52242, USA

Email: Rebecca A Roof - roofra@ninds.nih.gov; David L Roman - david-roman@uiowa.edu; Samuel T Clements - samtclem@umich.edu; Katarzyna Sobczyk-Kojiro - kkojiro@umich.edu; Levi L Blazer - llblazer@umich.edu; Shodai Ota - sota@umich.edu; Henry I Mosberg - him@umich.edu; Richard R Neubig* - rneubig@umich.edu

* Corresponding author
\end{abstract}

Published: 22 May 2009

BMC Pharmacology 2009, 9:9 doi:10.1186/147|-2210-9-9

This article is available from: http://www.biomedcentral.com/I47I-2210/9/9

(c) 2009 Roof et al; licensee BioMed Central Ltd.

This is an Open Access article distributed under the terms of the Creative Commons Attribution License (http://creativecommons.org/licenses/by/2.0), which permits unrestricted use, distribution, and reproduction in any medium, provided the original work is properly cited.
Received: 10 September 2008

Accepted: 22 May 2009

\begin{abstract}
Background: Regulators of G protein signaling (RGSs) accelerate GTP hydrolysis by $G \alpha$ subunits and profoundly inhibit signaling by $\mathrm{G}$ protein-coupled receptors (GPCRs). The distinct expression patterns and pathophysiologic regulation of RGS proteins suggest that inhibitors may have therapeutic potential. We recently described a focused one-bead, one-compound (OBOC) library screen to identify peptide inhibitors of RGS4. Here we extend our observations to include another peptide with a different mechanism of action.

Results: Peptide 5nd (Tyr-Trp-c [Cys-Lys-Gly-Leu-Cys]-Lys-NH ${ }_{2}$, S-S) blocks the RGS4-G $\alpha_{\text {。 }}$ interaction with an $\mathrm{IC}_{50}$ of $28 \mu \mathrm{M}$. It forms a covalent, dithiothreitol (DTT) sensitive adduct with a mass consistent with the incorporation of one peptide per RGS. Peptide $\mathbf{5 n d}$ activity is abolished by either changing its disulfide bridge to a methylene dithioether bridge, which cannot form disulfide bridges to the RGS, or by removing all cysteines from the RGS protein. However, no single cysteine in RGS4 is completely necessary or sufficient for $\mathbf{5 n d}$ activity.
\end{abstract}

Conclusion: Though it has some RGS selectivity, 5 nd appears to be a partially random cysteine modifier. These data suggest that it inhibits RGS4 by forming disulfide bridges with the protein.

\section{Background}

G Protein-Coupled Receptors (GPCRs) are a family of over 800 proteins that contain seven transmembrane regions [1]. When activated by agonists, such as hormones, neurotransmitters, drugs, or photons of light, GPCRs stimulate exchange of GTP for GDP on the Ga subunit of the heterotrimeric G protein, which then undergoes an activating conformational change that allows it and its associated $\beta \gamma$ subunit to interact with effector proteins [2]. This can result in a number of downstream signaling events including changes in membrane potential, neurotransmitter or hormone release, gene 
transcription or other cellular events [1]. The G $\alpha$ subunit inactivates itself by hydrolyzing GTP to GDP allowing reassociation with G $\beta \gamma$ and the receptor. Unlike GTPase accelerating proteins (GAPs) for small G-Proteins, regulators of $G$ protein signaling (RGS) proteins bind to the activated $\mathrm{G} \alpha$ protein and stabilize the transition state for GTP hydrolysis without directly interacting with the nucleotide $[3,4]$. This accelerates GTP hydrolysis and inactivation of the G-protein, and inhibits cell responses to GPCR signaling.

We recently reported the screening of a focused, one-bead, one-compound (OBOC) peptide library for inhibitors of RGS4 [5]. This library was focused to include features known to be necessary for the activity of a lead peptide, YJ34 (Ac-Val-Lys-c [Cys-Thr-Gly-Ile-Cys]-Glu- $\mathrm{NH}_{2}$, S-S) which mimics the switch 1 region of Ga to bind to RGS4 and prevent its GAP activity [6]. This screen yielded two peptides, which have YJ34-like activities and, based on our models, bind the predicted YJ34 site on RGS4. Here we describe a third peptide from the library screen that has a different mechanism of action. The data presented here suggest that peptide 5nd (Tyr-Trp-c [Cys-Lys-Gly-LeuCys]-Lys- $\mathrm{NH}_{2}$, S-S, peptide 7nd in Roof et al, 2008), is a partially random cysteine modifier that inhibits RGS4 through disulfide bond formation between the peptide and the RGS.

\section{Results and discussion}

We recently described a bead-based screen in which $2.5 \times$ $10^{6}$ different peptide sequences were prepared as a OBOC library [5]. Fluorescently labeled RGS4 was used to probe the library for peptides that bind RGS4 [5]. A total of 14 peptide sequences were obtained and, in our first report, one peptide sequence (in two chemical forms) was found to inhibit RGS4-stimulated GTPase activity. Since the majority of those hit peptides could bind tightly to the RGS without disrupting GAP activity, they were also tested in the flow cytometry protein interaction assay (FCPIA) (Figure 1), which measures the interaction between RGS4 and $\mathrm{G} \alpha_{0}$. In this method we used a Luminex flow cytometer to detect the binding of Alexa Fluor 532-labeled $\mathrm{G} \alpha_{\mathrm{o}}$ to biotinylated RGS4 on avidin beads in the presence of AMF ( $\mathrm{AlCl}_{3}, \mathrm{MgCl}_{2}, \mathrm{NaF}$ and GDP) to put the G $\alpha$ subunit into a transition state-like conformation [7]. Peptides were tested at $50 \mu \mathrm{M}$ except where limited by solubility (Table 1). Fourteen peptide sequences obtained from the OBOC screen, in both acetylated, disulfide bridged (ad) or free N-terminal disulfide bridged (nd) versions (or 28 peptides total), were tested and 5 showed statistically significant inhibition of the RGS4-Go $\alpha_{\mathrm{o}}$ interaction in the FCPIA assay (2nd, 5nd, 5ad, 6 nd and 6 ad, Figure 1, Table $1)$. Peptide 5 was the most active $(80 \pm 5$ and $37 \pm 3$ percent inhibition for 5 nd and 5ad, respectively) (Figure 1). 5nd inhibited $\mathrm{G} \alpha_{\mathrm{o}}$ binding to a number of different RGS proteins (Figure 2). The $\mathrm{IC}_{50}$ values are $28 \mu \mathrm{M}, 43 \mu \mathrm{M}, 66$ $\mu \mathrm{M}, \sim 145 \mu \mathrm{M}$ and $\sim 175 \mu \mathrm{M}$ for RGS4, RGS8, RGS16, RGS19 and RGS7, respectively $\left(\operatorname{logIC} \mathrm{C}_{50}\right.$ of $-4.56 \pm 0.02$, $4.36 \pm 0.02,-4.18 \pm 0.03, \sim-3.84 \pm 0.05$ and $\sim-3.76 \pm$ $0.08)$. The most potent effects were on RGS4, RGS8 and RGS16, which all belong to the same RGS family (R4) and share the greatest sequence homology. RGS19 and RGS7 are in the RZ and R7 families, respectively and show less inhibition by 5 nd. Linear as well as bridged versions of peptide 5 were tested in the FCPIA since cyclization yields would most likely have been less then $100 \%$ in the synthesis of the library leaving some linear peptides present on each bead. The free N-terminal linear ( $\mathrm{nl}$ ) and acetylated linear (al) peptides were found to be inactive ($1 \pm 10$ and $-2 \pm 4$ percent inhibition for $5 \mathrm{nl}$ and $5 \mathrm{al}$, respectively) (Figure 2C). This may be due to lack of structural rigidity necessary for the correct interaction of the peptide with the RGS protein or a role for chemical reactivity of the disulfide.

We next wanted to determine the mechanism of action of peptide 5. A small molecule inhibitor of RGS4, methyl N[(4-chlorophenyl)sulfonyl]-4-nitrobenzenesulfinimidoate (CCG-4986) was identified in a FCPIA screen and found to interact with RGS4 through cysteine modification $([7,8]$, David Roman, in preparation). We wanted to determine if peptide 5 nd acts in a similar manner. When biotin-RGS4 on avidin beads was treated with 5nd, followed by washing of the beads, the inhibition of RGS4$\mathrm{G} \alpha_{\mathrm{o}}$ interactions was not reversed $(75 \pm 11$ percent inhibition remained). Inclusion of dithiothreitol (DTT) in the wash buffer significantly decreased 5 nd activity $(15 \pm 4$ percent inhibition) (Figure 3A). These data suggest that the peptide may bind irreversibly through a disulfide bridge. To further investigate this possibility, a free N-terminal, methylene dithioether bridged peptide, $5 \mathrm{~nm}$ (Table 1), was synthesized and found to be inactive $(3 \pm$ 0.1 percent inhibition) (Figure $3 \mathrm{~A}$ ). Since the methylene dithioether bridged peptide would be incapable of forming a disulfide bond with RGS4, this result supports the hypothesis that $\mathbf{5 n d}$ forms a functionally critical disulfide bridge with RGS4. Although, it is also possible that the structural change from the increased bridge length is responsible for the loss of activity of $\mathbf{5 n m}$ compared to 5nd. A similar pattern was seen with RGS8; the loss of activity of 5nd on RGS8 was much greater with washing if DTT was included in the buffer and $5 \mathrm{~nm}$ had only a small effect on RGS8 activity $(64 \pm 2,50 \pm 3,10 \pm 3$, and $18 \pm 1$ percent inhibition for 5nd no wash, 5nd wash, 5nd DTT wash and $5 \mathrm{~nm}$ respectively) (Figure $3 \mathrm{~B}$ ).

To directly test for the formation of a covalent adduct between 5nd and RGS4, we performed mass spectrometry (MS) analysis. The RGS4 $\triangle 51 \mathrm{~N}$ protein, following TEV- 


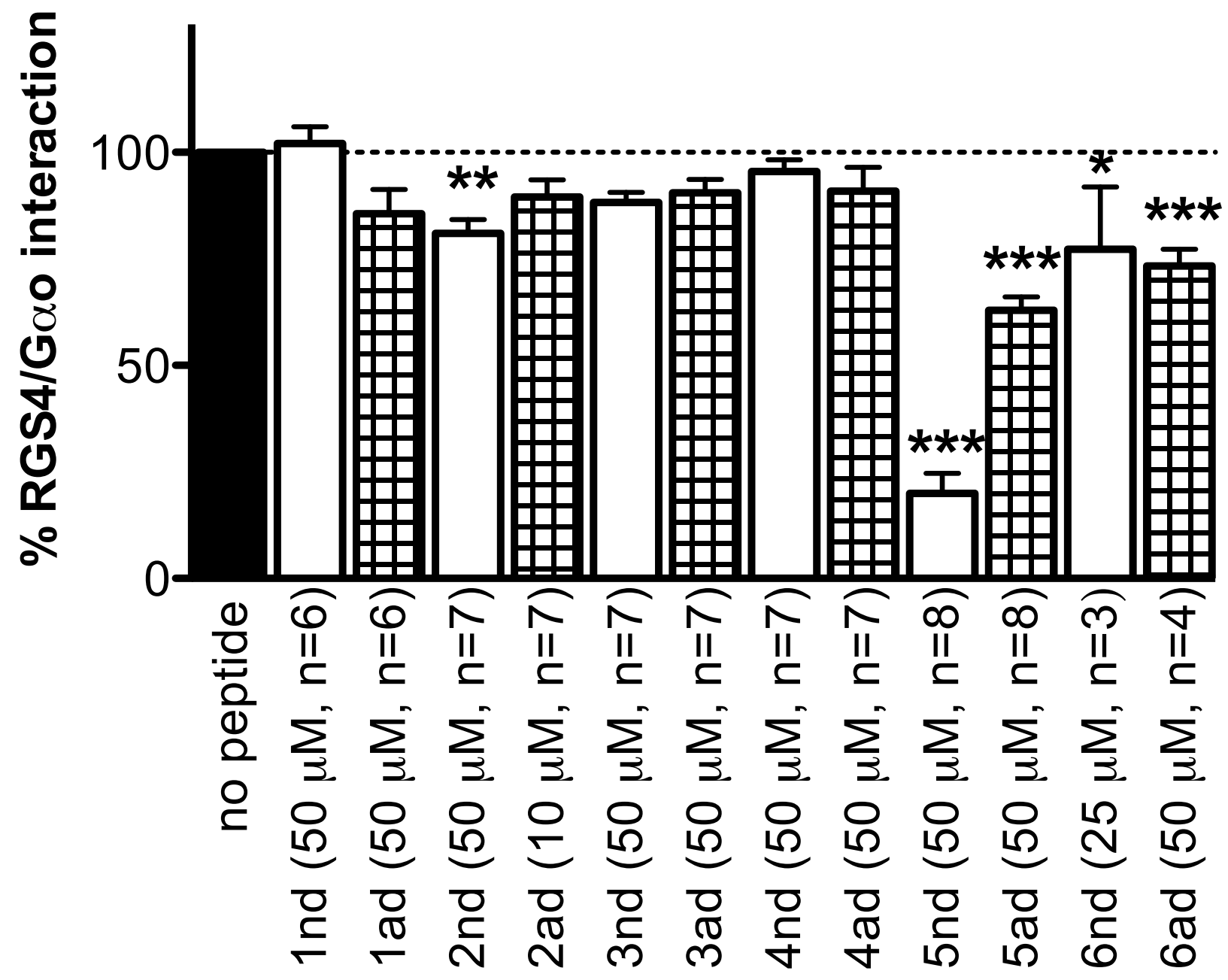

Figure I

Hit peptides in the FCPIA. Hit peptides from Roof, et al. 2008 were tested at $50 \mu M$ unless otherwise indicated for ability to disrupt the RGS4-G $\alpha_{0}$ interaction as described using $25 \mathrm{nM} \mathrm{G \alpha}$ o-Alexa Fluor-532 and 5 nM wild type RGS4-biotin (mean \pm S.E.M., $n \geq 3) *_{p}<0.05$, **p $<0.01$, ***p $<0.001$ compared to no peptide.

protease cleavage from the $\mathrm{MBP}-\mathrm{His}_{6}$ construct, was treated with 5nd at a 50:1 molar ratio. An adduct to the protein that is consistent with the mass of 5 nd binding through a disulfide bridge was observed by MS (Figure 4, mass shift observed: $\Delta 999.2 \pm 1$; expected: $\Delta 998.5)$. No such shift was observed with DMSO-treated RGS4 $451 \mathrm{~N}$. There is also a small peak that may represent two peptides per RGS (observed: $\Delta 1999.1 \pm 2$; expected: $\Delta 1997.0$ ).

Since 5nd forms an irreversible, DTT-sensitive bond with RGS, it was suspected that it binds covalently to a cysteine in the protein through a disulfide bridge. Indeed, removal of all 7 cysteines (termed the -7C mutant) from RGS4 greatly diminished 5 nd activity $\left(\log \mathrm{C}_{50}\right.$ of $-3.24 \pm 0.14$ for $-7 \mathrm{C}$ vs. $-4.36 \pm 0.02$ for wild type) (Figure 5, Table 2) Removal of cysteines from the C-terminus of RGS4 had no effect on the potency of 5 nd $\left(\log \mathrm{IC}_{50}-4.5 \pm 0.2\right)$ while removal of all 4 cysteines from the RGS domain did reduce the potency of compound by 3.6-fold $\left(\operatorname{logIC} \mathrm{C}_{50}-3.8\right.$ \pm 0.2 ) (Figure $5 \mathrm{E}$, Table 2 ). These results suggest a complex mechanism involving cysteines in both the C-terminus and RGS domain based on the discrepancy in 5nd potency on the $-7 \mathrm{C}$ mutant and the protein with no cys in the RGS domain.

To further explore the role of cysteine residues, the RGS proteins tested in Figure 2 were aligned with RGS4 (Figure $6)$ to identify shared cysteines. Based on the conservation 
Table I: Hit peptide names, sequences and physical properties

\begin{tabular}{|c|c|c|c|c|c|}
\hline Name & Sequence & cyclization & Buffer Solubility $(\mu \mathrm{M})$ & ALogP & $\%$ Inhibition of RGS4-G $\alpha_{\circ}$ \\
\hline YJ34 & $\mathrm{AC}-\mathrm{VKCTGICE}-\mathrm{NH}_{2}$ & S-S & 80 & -2.58 & $-17 \pm 4(40 \mu \mathrm{M})$ \\
\hline Ind & YNCQGECK- $\mathrm{NH}_{2}$ & S-S & $\geq 420$ & -2.8 & $2 \pm 4$ \\
\hline lad & $\mathrm{AC}-\mathrm{YNCQGECK}-\mathrm{NH}_{2}$ & S-S & 123 & -2.37 & $14 \pm 6$ \\
\hline 2nd & GTCFGTCW- $\mathrm{NH}_{2}$ & S-S & 464 & -0.37 & $19 \pm 3 * *$ \\
\hline $2 \mathrm{ad}$ & AC-GTCFGTCW-NH ${ }_{2}$ & S-S & 30 & 0.08 & $10 \pm 4(10 \mu \mathrm{M})$ \\
\hline 3nd & LVCKGYCQ $-\mathrm{NH}_{2}$ & S-S & $\geq 470$ & -0.37 & $12 \pm 2$ \\
\hline 3ad & $\mathrm{AC}-\mathrm{LVCKGYCQ}-\mathrm{NH}_{2}$ & S-S & 427 & 0.17 & $10 \pm 3$ \\
\hline 4nd & KVCMGGCT- $\mathrm{NH}_{2}$ & S-S & $\geq 470$ & -2.02 & $4 \pm 3$ \\
\hline $4 a d$ & $\mathrm{AC}-\mathrm{KVCMGGCT}-\mathrm{NH}_{2}$ & S-S & 459 & -2.09 & $9 \pm 6$ \\
\hline $5 \mathrm{nl}$ & YWCKGLCK- $\mathrm{NH}_{2}$ & Linear & 465 & 1.46 & $-1 \pm 10$ \\
\hline $5 \mathrm{al}$ & $\mathrm{AC}-\mathrm{YWCKGLCK}-\mathrm{NH}_{2}$ & Linear & 460 & 1.66 & $-2 \pm 4$ \\
\hline 5nd* & YWCKGLCK $-\mathrm{NH}_{2}$ & S-S & 463 & 0.48 & $80 \pm 5 * * *$ \\
\hline $5 a^{*} *$ & $\mathrm{AC}-\mathrm{YWCKGLCK}-\mathrm{NH}_{2}$ & S-S & 464 & 1.04 & $37 \pm 3 * * *$ \\
\hline $5 \mathrm{~nm}$ & YWCKGLCK $-\mathrm{NH}_{2}$ & S-me-S & $\geq 470$ & 0.53 & $3 \pm 0.1(100 \mu \mathrm{M})$ \\
\hline 6nd* & KHCYGFCY $-\mathrm{NH}_{2}$ & S-S & Low & 0.94 & $23 \pm 15(25 \mu \mathrm{M}) *$ \\
\hline 6ad* & $\mathrm{AC}-\mathrm{KHCY} G \mathrm{FCY}-\mathrm{NH}_{2}$ & S-S & 421 & 1.24 & $27 \pm 4^{* * *}$ \\
\hline
\end{tabular}

Solubility in buffer was determined experimentally by HPLC. ALogP calculations are from http://www.vcclab.org, [9]. Percent inhibition values (50 $\mu \mathrm{M}$ unless otherwise stated) are from Figure I, 2 C, or $3 \mathrm{~A}$ (mean \pm S.E.M., $\mathrm{n} \geq 3$ ) ${ }^{*} \mathrm{p}<0.05$, ${ }^{* *} \mathrm{p}<0.0 \mathrm{I}$, *** $<<0.00 \mathrm{I}$ compared to no peptide. Peptides with significant inhibition in the FCPIA are in bold. *Peptides 5 and 6 were previously reported as peptides 7 and I4, respectively in Roof et al 2008.

of Cys95 and Cys148 in RGS4 RGS8 and RGS16, which are all inhibited by 5 nd, it was hypothesized that those cysteines may be involved in the peptide's activity. However, removing those cysteines individually (i.e. in the C95A and C148A mutant RGS4) did not diminish 5nd activity $\left(\log _{50}-4.71 \pm 0.0 .5\right.$ and $-4.27 \pm 0.05$ for $\mathrm{C} 95 \mathrm{~A}$ and C148A, respectively) (Figure 5A, Table 2). Because all the mutants used in this manuscript bound $\mathrm{G}_{\mathrm{o}}$ in an AMF-dependent manner with reasonable affinities compared to wild type (Table 2), it is reasonable to assume they are folded properly. With the assumption that $5 \mathrm{nd}$ would have to bind within the RGS domain to inhibit $\mathrm{G} \alpha_{\mathrm{o}}$ binding, C71A and C132A mutations were also tested. The C71A mutation did not affect 5 nd activity $\left(\log \mathrm{IC}_{50}\right.$ $4.34 \pm 0.06)$. The $\mathrm{C} 132 \mathrm{~A}$ mutation did decrease 5nd potency, but only partially $\left(\log \mathrm{IC}_{50}-3.86 \pm 0.07\right)$ (Figure $5 \mathrm{~B}$, Table 2). Interestingly, $\mathrm{C} 132$ is near the $\mathrm{G} \alpha$ binding site, which is also the suggested YJ34 binding site. It is tempting to speculate that one of the multiple sites of action of 5 nd is adjacent to the G $\alpha$ binding site (similar to that of YJ34), however, the A132C "add back" mutant discussed below again suggests a complex scenario.

The previous experiments tested which cysteines are necessary for inhibition by 5 nd. In an alternative approach, we added cysteines back to the -7C mutant to determine which might be sufficient for 5nd activity. Surprisingly, no single A to $\mathrm{C}$ mutation within the RGS domain of the $-7 \mathrm{C}$ mutant even partially restored 5nd activity; not even the A132C mutant (Figure 5C, Figure 5D, Table 2). This suggests that 5 nd inhibits RGS4/G $\alpha_{\mathrm{o}}$ interactions by binding to multiple cysteines - probably in both the RGS domain and the C-terminus. Furthermore, Cys132 is involved in the actions but this is clearly not sufficient to 

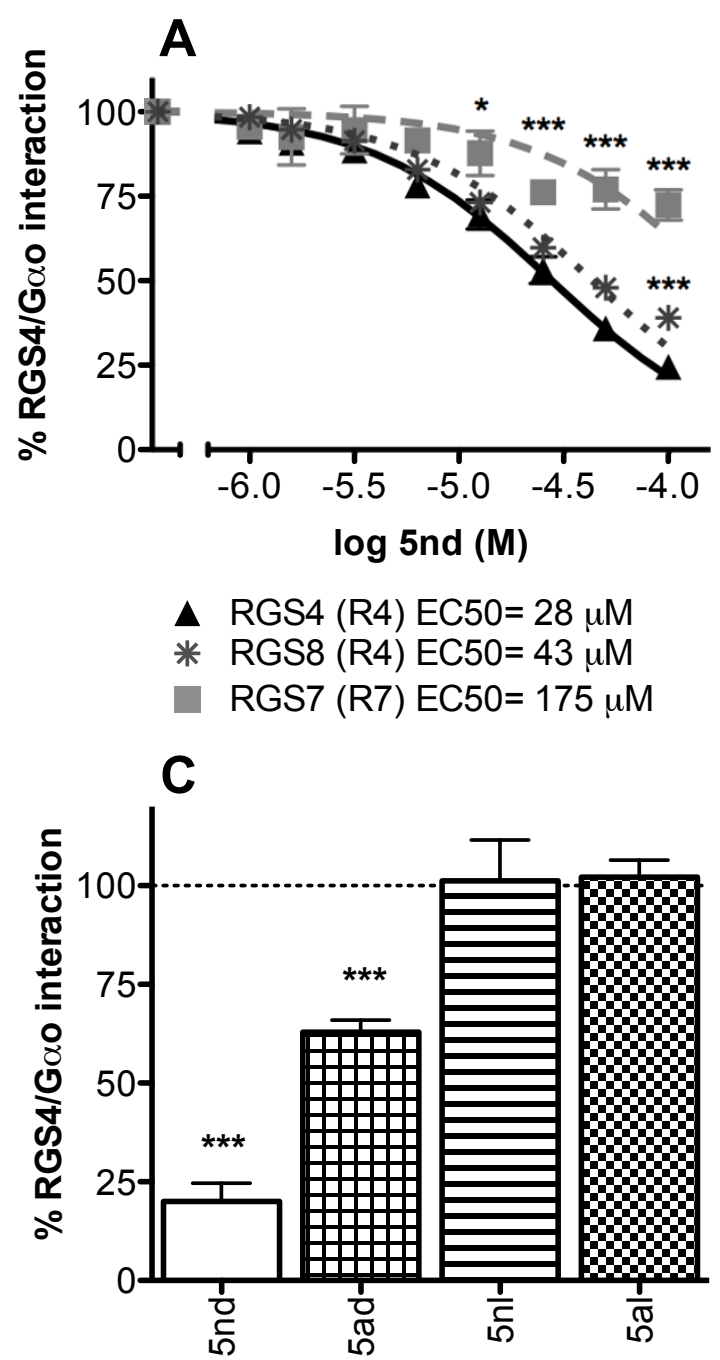

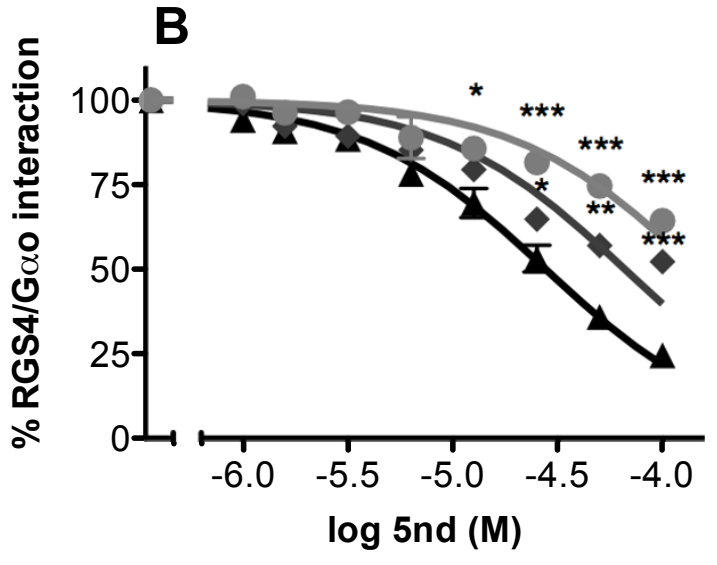

$\begin{array}{ll}\Delta & \text { RGS4 (R4) EC50 }=28 \mu \mathrm{M} \\ \text { RGS16 (R4) EC50 }=66 \mu \mathrm{M} \\ \text { RGS19 (RZ) EC50 }=145 \mu \mathrm{M}\end{array}$

Figure 2

Characterization of hit 5. A) and B) Dose response curves for 5 nd in the FCPIA with different RGS proteins (RGS Family), (mean \pm S.E.M., $n=3$ ) * $p<0.05$, ** $p<0.01$, *** $p<0.001$ compared to RGS4 at the same 5nd concentration. C) Peptides were tested at $50 \mu \mathrm{M}$ as in Figure I, (mean \pm S.E.M., $n \geq 3$ ) ${ }^{*} p<0.05$, $*_{p} *_{p}<0.0$ I, $*^{*} *_{p}<0.00$ I compared to no peptide.

explain them. Thus it is concluded that $5 \mathrm{nd}$ is at least partially non-selective in its cysteine modification. These data also suggest RGS4 is more sensitive to covalent redox manipulations than are the other RGS proteins tested.

In summary, peptide 5nd binds covalently through disulfide bridges with cysteines in the protein and it raises some interesting points regarding the previously reported focused OBOC screen [5]. First, it is interesting that although the library was focused to include features necessary for YJ34 activity, peptide 5nd was isolated that clearly works through a different mechanism. This was unexpected since the library was biased towards peptides that would have the same mechanism as the lead compound. However, this bias is by no means a guarantee. Indeed, there is no way to know whether a peptide like hit 2, (which has YJ34-like activities and is modeled to bind the putative YJ34 site on RGS4, [5]) would have been found from a completely random library.

Another interesting observation is that RGS4 is preferentially inhibited by the cysteine modifier peptide over other RGS proteins. This could be because the peptide binds selectively to a pocket on RGS4, or because RGS4 is 

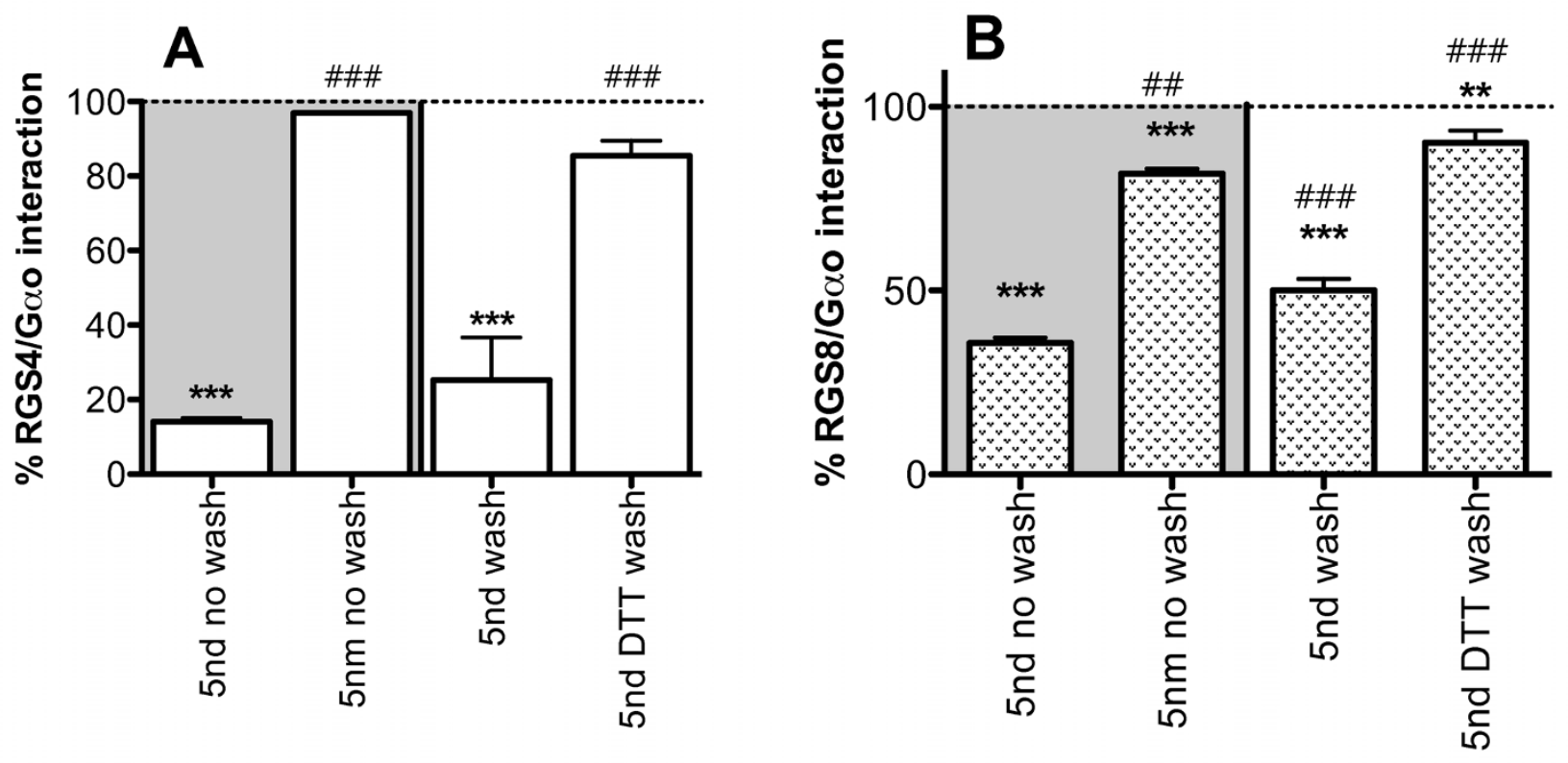

\section{Figure 3}

Irreversibility experiments. RGS-biotin on avidin beads was treated with $\mathbf{5 n d}(100 \mu \mathrm{M})$ or $\mathbf{5 n m}(100 \mu \mathrm{M})$ and then washed in buffer (with or without I mM DTT) or not washed and put in the FCPIA using RGS4 (A) or RGS8 (B) (mean \pm

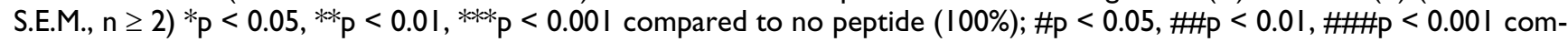
pared to 5 nd no wash.

particularly susceptible to cysteine modification. This latter possibility is supported by the observation that a small molecule inhibitor of RGS4, CCG-4986, that was identified in an FCPIA screen appears to inhibit RGS4 through covalent modification of cysteines while having no activity against RGS8 ([7,8], David Roman, in preparation). Also, RGS4 is more sensitive to inhibition with N-ethylmaleimide, (a cysteine modifier) than RGS8 (David Roman, personal communication). Unlike 5nd, CCG4986 appears to selectively modify 1 or 2 cysteines in the RGS4 ([7,8], David Roman, in preparation). This increased cysteine selectivity may be why CCG-4986 has more RGS selectivity than 5nd. However, since all peptides in our library have a disulfide bond, it is not clear why 5nd (and 5ad) would be so much more potent at covalently modifying RGS4. Perhaps the cysteine reactive peptide also has some affinity for a specific pocket on the RGS.

A third observation is that there may be a correlation between peptide $\operatorname{logP}$ and activity in the FCPIA (Table 1 ). The order of activity in the FCPIA is hit $\mathbf{5}>$ hit $\mathbf{6}>$ hit $\mathbf{2}>$ others [9], while the order of hydrophobicity is hit $6>$ hit $5>$ hit $3>$ hit $2>$ others. Given the considerable error in computational $\log P$ calculations [10], it is reasonable to suggest at least qualitatively that the most hydrophobic peptides have the greatest activity. This also tells us something about RGS4. These data suggest that RGS4 binding sites, including unidentified binding sites, have hydrophobic surfaces and investigators should be mindful of this when choosing libraries for future screens.

\section{Conclusion}

We report the identification and characterization of a peptide RGS4 inhibitor with a novel mechanism involving cysteine-modification. Although our focused OBOC screen did not improve on the potency of existing RGS4 inhibitors with, these data illustrate points that should result in improved screens in the future.

\section{Methods \\ Materials}

Fmoc-protected amino acids and Rink amide resin were purchased from Advanced ChemTech. Peptide synthesis grade chemicals were purchased from Applied Biosystems. Avidin coated microspheres were purchased from Luminex. 


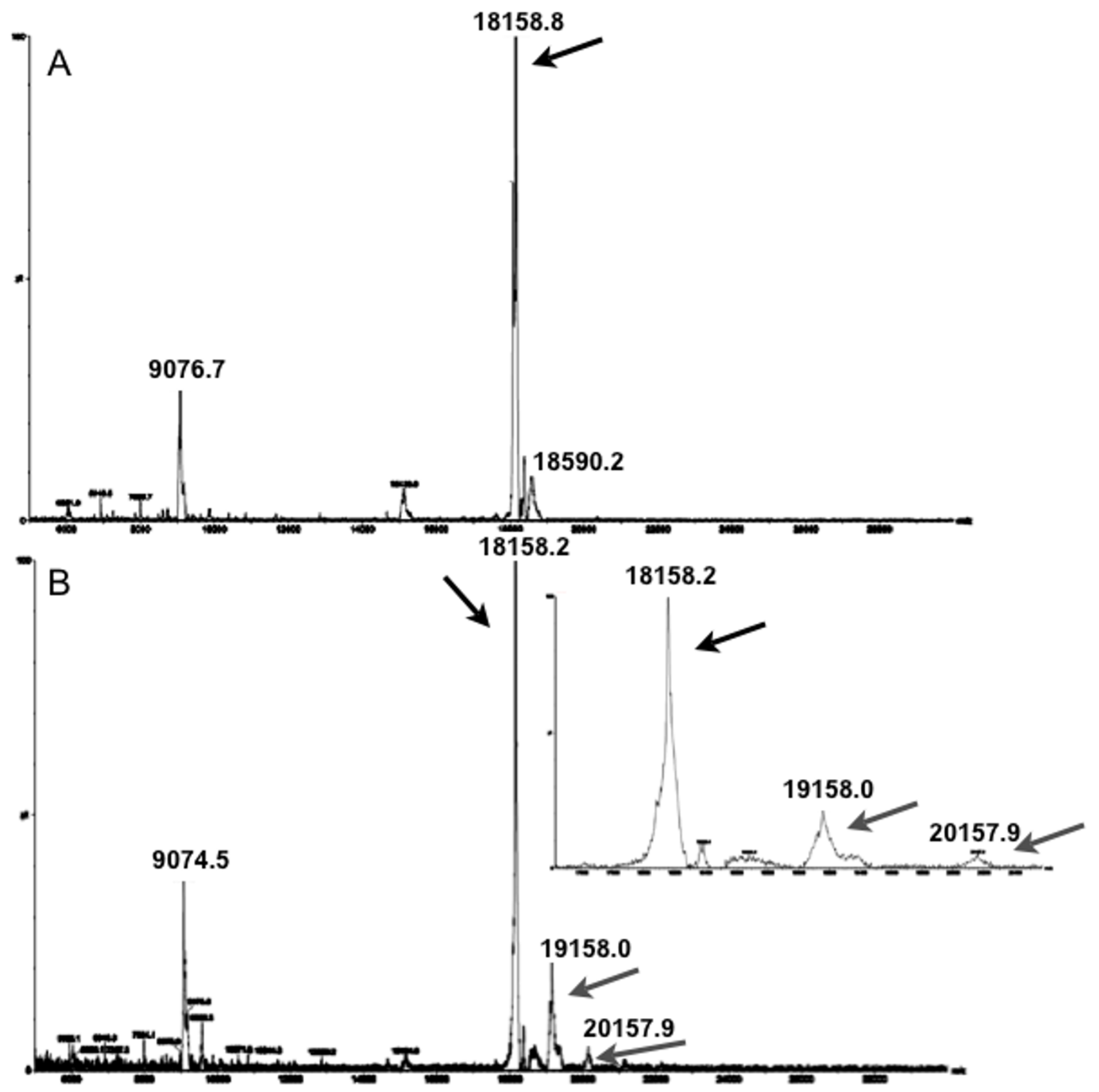

Figure 4

MS analysis of RGS4 with and without 5nd pretreatment. RGS4 5 IN was cleaved from the MBP-His 6 construct and subject to MALDI MS after pretreatment with DMSO (A) or 5nd $(250 \mu \mathrm{M})(\mathrm{B})$. Both spectra show the region between 4,000 and $30,000 \mathrm{~m} / \mathrm{z}$ and have the peak at 18158.8 or $18158.2 \mathrm{~m} / \mathrm{z}$ for $A$ and $B$, respectively, which corresponds to the cleaved RGS4 5 IN protein (black arrows). The spectrum in B also has a peak at $19158 \mathrm{~m} / \mathrm{z}$ that corresponds to a peptide adduct (grey arrows). There is a very small peak at 20157.9 that may correspond to 2 peptides per RGS (grey arrows). The inset is a blowup of the region between 17500 and $20500 \mathrm{~m} / \mathrm{z}$. 

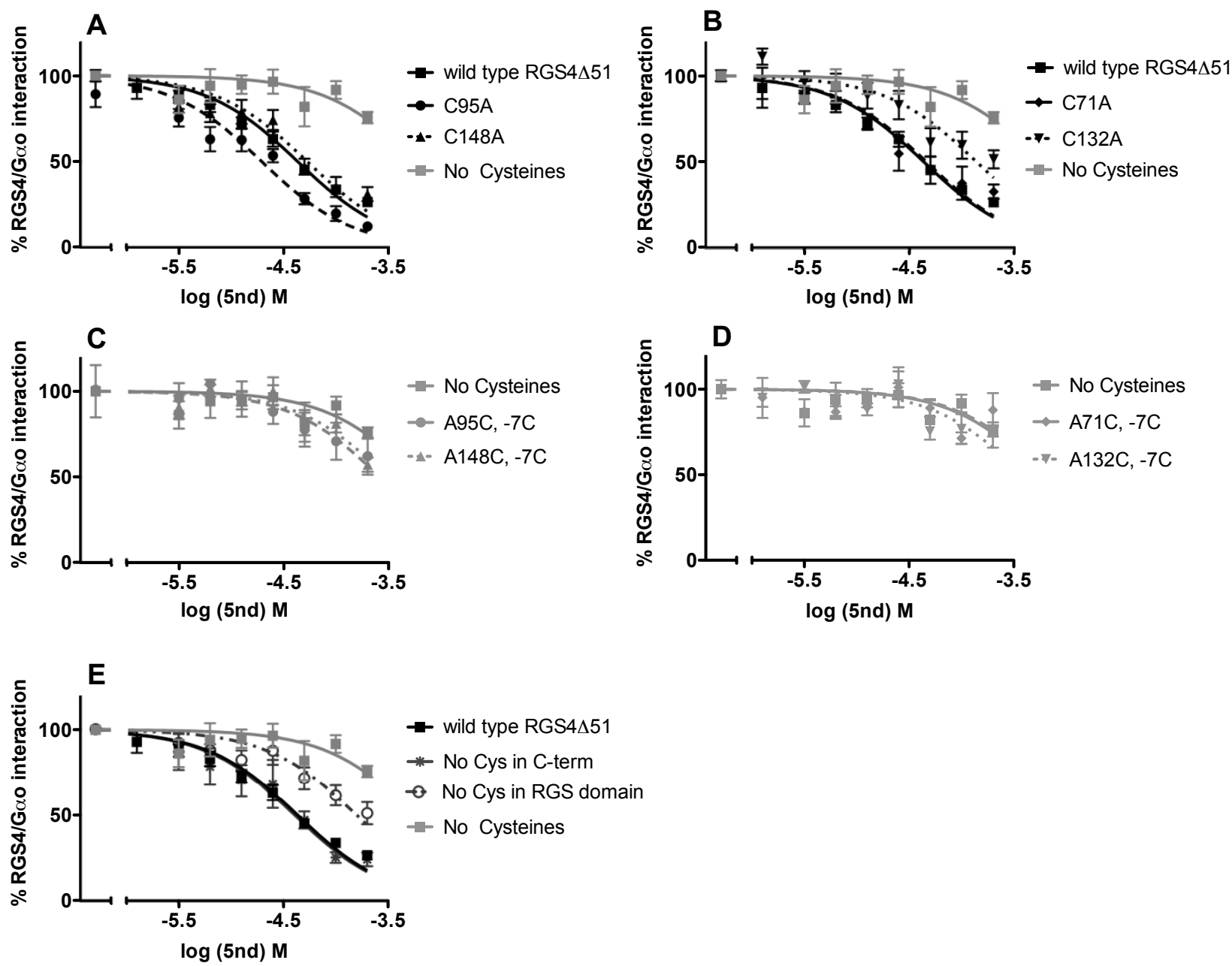

\section{Figure 5}

Dose curves of 5nd on various RGS4 cysteine mutants. Various concentrations of 5 nd were tested for disruption of the RGS4-G $\alpha_{0}$ interaction for C95A (5 nM), or CI48A (5nM) (A), C7IA (5nM) or CI48A (5nM) (B), A95C in the -7C (5nM), or $A I 32 C$ in the $-7 C(5 n M)(C), A 7 I C$ in the $-7 C(5 n M)$, or $A I 48 C$ in the $-7 C(5 n M)(D)$ or the mutant with no cysteines in the domain $(20 \mathrm{nM})$ or the C-terminus $(20 \mathrm{nM})(\mathrm{E})$ in the FCPIA (mean \pm S.E.M., $\mathrm{n} \geq 3)$. See Table 2 for statistics.

\section{Protein Expression, Purification and Labeling}

Proteins were expressed, purified and labeled as described previously [5]. The mutagenesis was done using the "QuickChange Multi Site-Directed Mutagenesis Kit" from Stratagene according to the manufacturer's protocol. The construct of RGS4 used in these studies is a maltose binding protein (MBP-) fusion protein of the RGS4 sequence from which the amphipathic $\mathrm{N}$-terminal helix has been removed (i.e. MBP-RGS4 $\Delta 51 \mathrm{~N}$ ). For simplicity in the text, this will be referred to as RGS4. All other RGS proteins were human sequences and were used as Mpb fusions: RGS7 RGS domain (aa: 305-453), RGS8 full length, RGS16 full length, and RGS19 $\Delta$ C11 (amino acids 1-209). To cleave RGS $4 \Delta 51 \mathrm{~N}$ from the MBP-His ${ }_{6}$ construct for MS analysis, MBP-His ${ }_{6}-\mathrm{RGS} 4 \Delta 51 \mathrm{~N}$ was treated with $15 \%$ MBP-His $_{6}$-TEV protease S219V [11] for 22 hours at $4{ }^{\circ} \mathrm{C}$ and purified over a Ni-NTA column.

\section{Peptide Synthesis}

Soluble peptides were synthesized on Rink resin, cleaved and cyclized as described previously [6]. Peptide purity (at least 95\%) and solubility were verified by high-performance liquid chromatography and correct mass was verified by MS analysis [6]. ALogP calculations are from http:// www.vcclab.org[9]. Peptides were prepared as $5 \mathrm{mM}$ stocks in DMSO. 
Table 2: Mutant RGS4 $\mathrm{G}_{0}$ binding affinities and 5 nd $\log I \mathrm{C}_{50} \mathrm{~s}$.

\begin{tabular}{|c|c|c|}
\hline Mutant & $\mathbf{G} \alpha_{0}$ affinity (nM) & 5nd $\log I C_{50}(M)$ \\
\hline wild type & $11.6 \pm 1.4$ & $-4.36 \pm 0.03 \# \#$ \\
\hline C95A & $8.17 \pm 1.5$ & $-4.71 \pm 0.05 \ldots \#$ \\
\hline $\mathrm{Cl} 48 \mathrm{~A}$ & $6.84 \pm 1$ & $-4.27 \pm 0.05 \#$ \\
\hline C7IA & $12.2 \pm 1.8$ & $-4.34 \pm 0.06 \# \#$ \\
\hline $\mathrm{CI} 32 \mathrm{~A}$ & $7.9 \pm 3.1$ & $-3.86 \pm 0.07$ \\
\hline$-7 C$ & $8.3 \pm 1$ & $-3.24 \pm 0.14^{* * * *}$ \\
\hline A95C, -7C & $12 \pm 2$ & $-3.58 \pm 0.09 * *$ \\
\hline Al $48 \mathrm{C},-7 \mathrm{C}$ & $5.7 \pm 0.2$ & $-3.51 \pm 0.09 * *$ \\
\hline A7IC, $-7 C$ & $9.2 \pm 2$ & $-3.20 \pm 0.13^{* *}$ \\
\hline $\mathrm{A} 132 \mathrm{C},-7 \mathrm{C}$ & $12.5 \pm 1$ & $-3.41 \pm 0.09 * *$ \\
\hline no Cys in RGS domain & $3.9 \pm 0.8$ & $-3.80 \pm 0.06^{*}$ \\
\hline no Cys in C-terminus & $5.0 \pm 0.7$ & $-4.39 \pm 0.07 \# \#$ \\
\hline
\end{tabular}

$\mathrm{G} \alpha_{\mathrm{o}}$ affinities were calculated in the FCPIA as described and logIC $\mathrm{C}_{50}$ data is from Figure 5. (mean \pm S.E.M., $\mathrm{n} \geq 3$ ) ${ }^{*} \mathrm{p}<0.05,{ }^{* *} \mathrm{p}<0.0 \mathrm{I},{ }^{* * *} \mathrm{p}<0.00 \mathrm{I}$ compared to wild type RGS4 $\triangle 5 \mathrm{IN}$; \#p $<0.05$, \#P $<0.01$, \#\# $<0.001$ compared to -7C RGS4 $\triangle 5 \mathrm{IN}$.

FCPIA (Flow Cytometry Protein Interaction Assay) FCPIA was performed as previously published [7].

\section{Mass Spectrometry}

Total mass MS of $5 \mu \mathrm{M}$ RGS $4 \Delta 51 \mathrm{~N}$ was analyzed on a MicroMX MALDI MS instrument in positive ion mode with an accuracy of $\pm 0.1 \%$ after pretreatment with DMSO or $250 \mu \mathrm{M}$ 5nd. The sample was run over a desalting column prior to MS analysis. MS analysis was performed at the Protein Structure Facility at the University of Michigan.

\section{Statistical Analysis}

Data are expressed as mean \pm S.E.M (or \pm S.D for $n=2$ ) and analyzed by one-way ANOVA. Dose curves were constrained with maximum and minimum at $100 \%$ and $0 \%$, respectively. Statistics for Figure 5 are included in Table 2 instead of on the graph for simplicity. Significance is indicated as follows: ${ }^{*} \mathrm{p}<0.05,{ }^{* *} \mathrm{p}<0.01,{ }^{* * *} \mathrm{p}<0.001$. Analysis was performed using Graphpad Prism.

\section{Abbreviations}

AMF: $\mathrm{AlCl}_{3}, \mathrm{MgCl}_{2}, \mathrm{NaF}$ and GDP; ANOVA: analysis of variance; DMSO: dimethylsulfoxide; DTT: dithiothreitol; GAP: GTPase accelerating protein; GPCR: G protein-coupled receptor; GTP: guanosine triphosphate; FCPIA: flow cytometry protein interaction assay; OBOC: one-bead, one-compound; RGS: regulator of G protein signaling; SAR: structure activity relationship.

\section{Authors' contributions}

RR, HM, and RN conceived the project; RR synthesized the library and ran the initial screen. She also synthesized some of the peptides, prepared some of the proteins, designed and performed the FCPIA experiments except Figure 2 which was performed by STC. RR also analyzed the data, prepared samples for MS, and drafted the manuscript. DR taught RR the FCPIA assay, designed and carried out most of the DNA mutagenesis, prepared and labeled many of the proteins used, and determined $\mathrm{G} \alpha_{\mathrm{O}}$ affinities for most of the RGS $4 \Delta 51 \mathrm{~N}$ mutants. KS provided assist- 


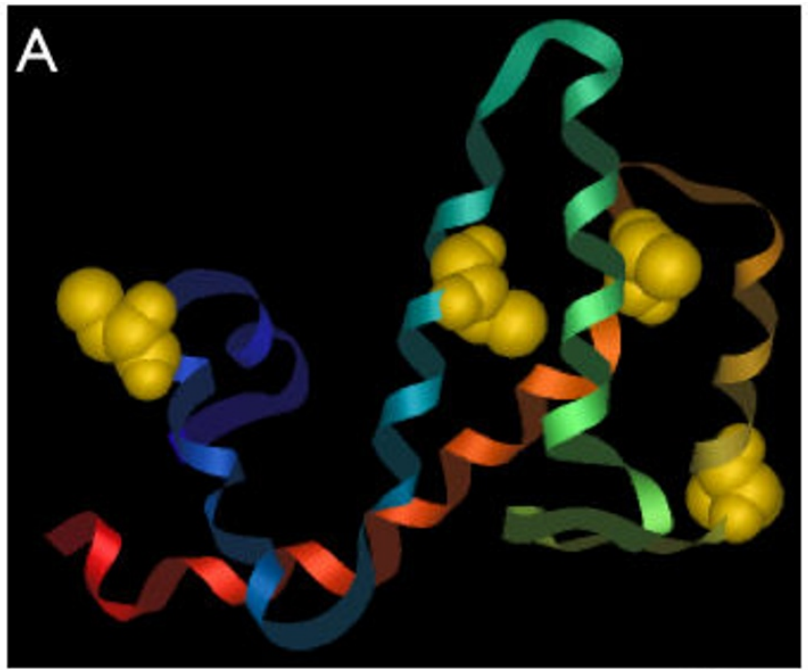

71

B RGS4 vsqeevkkwa

RGS8 is teeat rwa RGS16 sf sedvigwr RGS19 pspeevqswa RGS7 psqqrvkrwg es I en I ishe ds f d v I I sh k e s f q I I n sk qs $\mathbf{f g k I m h} \mathbf{~ p ~}$ f gmd e a I kdp $* * * * *$

RGS4 akkiynefis vqatkevnid

RGS8 ahrifeefvd vqaprevnid

RGS16 ahhifdeyir seapkevnid

RGS19 arliyedyvs i Ispkevs Id

RGS7 vqeiwqefla

\section{pgapsainid}

183

RGS4 srsyld I vnp ss cgaekqkg
RGS8 skmyId I Is-
RGS16 spayrd Ia a a s a
RGS19 sptyra I I I q gpsqssse--
RGS7 ssayqe I I qa krksgnsmdr c.g I a f kaf I ygvaaf $r$ af I ngva a f haf I agrsvfrafi vareqfikfi 132. sctireets $r$ f q $\mathrm{t}$ eat $\mathrm{rkn}$ het rel t k t n s rvregi nkk sks ydkt $\mathrm{qn}$

197

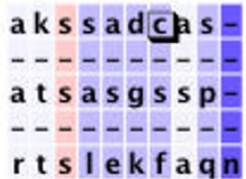

$* * * * *$ kseyseen id kt ef seen l e k tefseenle $r$ teyseenm I esefssenir 148

\section{mlept i teff} I qeps I t c f d I qaat pscid mqepsaht fd vkepgrytfe

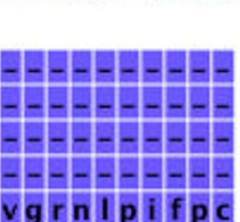

95

f wiscleykk ikspsk Ispk f wlaclefkk trstak I vsk f wl aceefkk i rsatk Ias fwI acee I ka eanqhvvdek fwiaved ikr - rpirevpsr

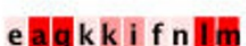

qagkvhs im vaqgktrt Im daq I q i y t Im daqe h i y k I m

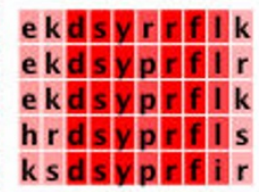
204

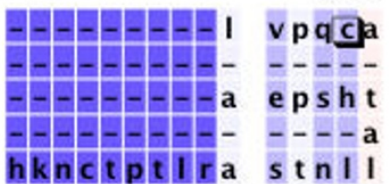

Figure 6

RGS alignment. A) The structure of the RGS4 domain [3] with the cysteines highlighted. B) An alignment of the RGS proteins used in Figure 3 compared to the RGS4 5 IN construct. The RGS proteins are listed in order of inhibition by 5 nd. The red residues are conserved and the blue are not. The stared residues are important for $\mathrm{G} \alpha$ interactions and the cysteines in RGS4 are boxed.

ance and advice with the peptide synthesis. $\mathrm{LB}$ and SO prepared some of the proteins used. RR, DR, LB, and SO all did some of the protein labeling. HM and RN oversaw the project. All authors read and approved the manuscript.

\section{Acknowledgements}

The authors would like to acknowledge Paul Kirchoff for assistance with the $\log \mathrm{P}$ analysis, Sue Wade for assistance with the manuscript, and John Tesmer for helpful discussions. We would like to acknowledge the support of the Michigan Chemistry-Biology Interface Training Program (RR, LB), which is funded through the National Institutes of Health under grant number T32 GM00008597. This work was also supported by DA003910 (HIM) and GM3956I and DA23252 (RRN). This research used the Protein
Structure Facility Core(s) of the Michigan Diabetes Research and Training Center supported by DK20572 and the DNA Sequencing Core supported by the University of Michigan Comprehensive Cancer Center (P30CA046592).

\section{References}

I. Pierce KL, Premont RT, Lefkowitz RJ: Seven-transmembrane receptors. Nat Rev Mol Cell Biol 2002, 3(9):639-650.

2. Hepler JR: Emerging roles for RGS proteins in cell signalling. Trends Pharmacol Sci 1999, 20(9):376-382.

3. Tesmer JJ, Berman DM, Gilman AG, Sprang SR: Structure of RGS4 bound to AIF4-activated $G(i$ alphal $)$ : stabilization of the transition state for GTP hydrolysis. Cell 1997, 89(2):25I-26I.

4. Berman DM, Kozasa T, Gilman AG: The GTPase-activating protein RGS4 stabilizes the transition state for nucleotide hydrolysis. J Biol Chem 1996, 27 I (44):27209-272I2. 
5. Roof RA, Sobczyk-Kojiro K, Turbiak AJ, Roman DL, Pogozheva ID, Blazer LL, Neubig RR, Mosberg HI: Novel Peptide Ligands of RGS4 from a One-Bead, One-Compound Library. Chem Biol Drug Des 2008, 72: III-119.

6. Roof RA, Jin Y, Roman DL, Sunahara RK, Ishii M, Mosberg HI, Neubig RR: Mechanism of action and structural requirements of constrained peptide inhibitors of RGS proteins. Chem Biol Drug Des 2006, 67(4):266-274.

7. Roman DL, Talbot JN, Roof RA, Sunahara RK, Traynor JR, Neubig RR: Identification of small-molecule inhibitors of RGS4 using a high-throughput flow cytometry protein interaction assay. Mol Pharmacol 2007, 7I(I):169-175.

8. Kimple AJ, Willard FS, Giguere PM, Johnston CA, Mocanu V, Siderovski DP: The RGS protein inhibitor CCG-4986 is a covalent modifier of the RGS4 Galpha-interaction face. Biochim Biophys Acta 2007, 1774(9): 1213-1220.

9. Tetko IV, Gasteiger J, Todeschini R, Mauri A, Livingstone D, Ertl P, Palyulin VA, Radchenko EV, Zefirov NS, Makarenko AS, Tanchuk VY, Prokopenko VV: Virtual computational chemistry laboratory design and description. J Comput Aided Mol Des 2005, 19(6):453-463.

10. Thompson SJ, Hattotuwagama CK, Holliday JD, Flower DR: On the hydrophobicity of peptides: Comparing empirical predictions of peptide log P values. Bioinformation 2006, I (7):237-24I.

11. Lucast LJ, Batey RT, Doudna JA: Large-scale purification of a stable form of recombinant tobacco etch virus protease. BioTechniques 200I, 30(3):544-6.

Publish with Bio Med Central and every scientist can read your work free of charge

"BioMed Central will be the most significant development for disseminating the results of biomedical research in our lifetime. "

Sir Paul Nurse, Cancer Research UK

Your research papers will be:

- available free of charge to the entire biomedical community

- peer reviewed and published immediately upon acceptance

- cited in PubMed and archived on PubMed Central

- yours - you keep the copyright

Submit your manuscript here:

http://www.biomedcentral.com/info/publishing_adv.asp
BiolMedcentral 